\title{
Influence of biomass burning from South Asia at a high-altitude mountain receptor site in China
}

\author{
Jing Zheng et al. \\ Correspondence to: Min Hu (minhu@pku.edu.cn)
}

The copyright of individual parts of the supplement might differ from the CC BY 3.0 License. 
Table S1. Overview of main instruments used during the campaign.

\begin{tabular}{cccc}
\hline Parameter & Phase & Instrument & Manufacturer \\
\hline NR-PM 1 composition & Particle & HR-ToF AMS & Aerodyne Research Inc, Billerica, MA, \\
BC & Particle & Aethalometer, type AE31 & Magee Scientific, Berkeley, CA, USA \\
Aerosol number size & Particle & SMPS (3081-DMA and & TSI Inc., Shoreview, MN, USA \\
distribution & & 3022-CPC) & \\
VOCs concentration & Gas & GC-MS/FID & Self-made instrument \\
\hline
\end{tabular}

\section{S.2 Comparisons between AMS and other instruments}

The sum of mass concentrations measured by the AMS (sulfate + nitrate + ammonium $+\mathrm{OA}$ ) and BC were compared to mass concentrations converted from volume concentrations measured by the SMPS by multiplying an estimated compositiondependent density. The aerosol density used was $1.4 \mathrm{~g} \mathrm{~cm}^{-3}$ for organics (Gysel et al., 2007), $1.75 \mathrm{~g} \mathrm{~cm}^{-3}$ for sulfate, nitrate and ammonium, and $1.80 \mathrm{~g} \mathrm{~cm}^{-3}$ for black carbon as suggested by Middlebrook et al. (2012). Given the decrease of the transmission efficiency of AMS at large size, the size range of the SMPS for integration was taken from 15 to $600 \mathrm{~nm}$ when doing the inter-comparison (Hu et al., 2013). The scatter plot of AMS plus BC vs. PM1 concentrations from SMPS showed a strong correlation $\left(\mathrm{R}^{2}=0.96\right)$ with a slope of 1.1 (Fig. S1).

\section{S.3 PMF diagnostics and evaluation}

PMF analysis was performed on the high resolution spectral matrix of organics provided by AMS. The data was analyzed according to the method recommend by Ulbrich et al. (2009). Factor numbers from 1 to 12 were tested to see if the solutions could successfully explain the variations of organic time series by several meaningful factors.

One factor or two factors would result in large residuals in both time series and key $\mathrm{m} / \mathrm{z}$ values, with high Q/Qexp values. A 3-factor solution has a low Q/Qexp values of 1.1, and further increasing the factor number only resulted in minor decreases in Q/Qexp values. The 3-factor solution has two similar OOA factors. The time series of one OOA factor presented noisy background, shown as fac1 in grey color in Fig. S2(b). The 4-factor solution could clearly identify two factors, and can be 
assigned as BBOA and OOA-BB. However the time series of the first factor was noisy as Fig. S3(b). The similarity in the spectra of factor 1 and factor 2 indicates that these two factors were essentially a split of one factor. When factor number went beyond 4, splits of factors also happened, as shown in the example of 5-factor solution in Fig. S4(a). as BBOA. Factor 1 and factor 2 were combined together to form a new factor by a mass-weighted averaging of their profiles, and was identified as OOA. The concentration of the combined factor equals to the sum of the concentrations of factor 1 and factor 2 .

The stability of the solution was further investigated by FPEAK rotational analysis and SEED method. Results showed very little variability at different FPEAK values, with FPEAK $=0$ being the lowest point in Fig.S5 (b). Thus FPEAK= 0 was values, as shown in Fig.S5 (d), proving that the solution of PMF was stable.

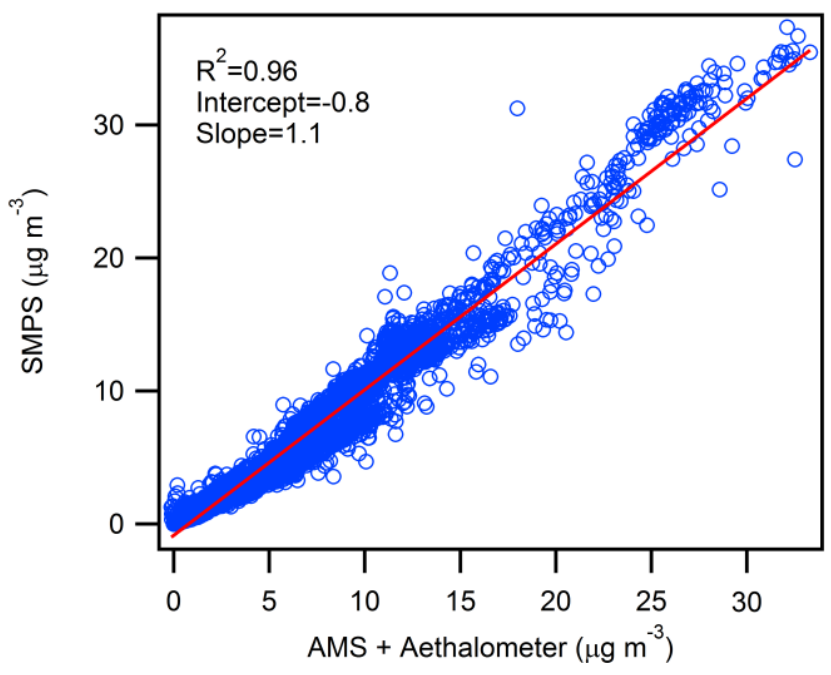

Figure S1. Comparison of the mass concentration of $\mathrm{PM}_{1}$ measured by SMPS 

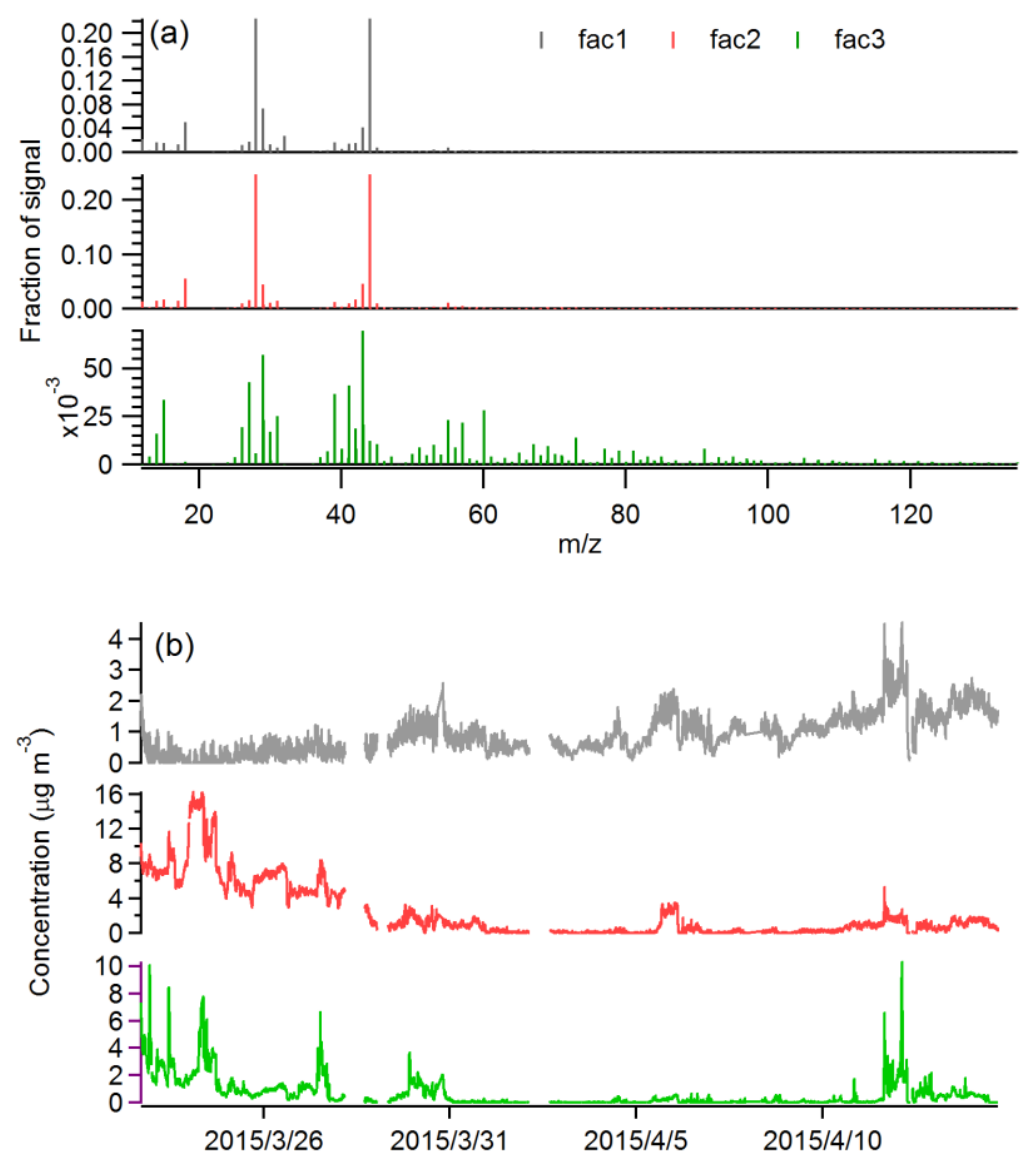

36

37

38

Figure S2. (a) mass spectra and (b) time series of the 3-factor solution. 

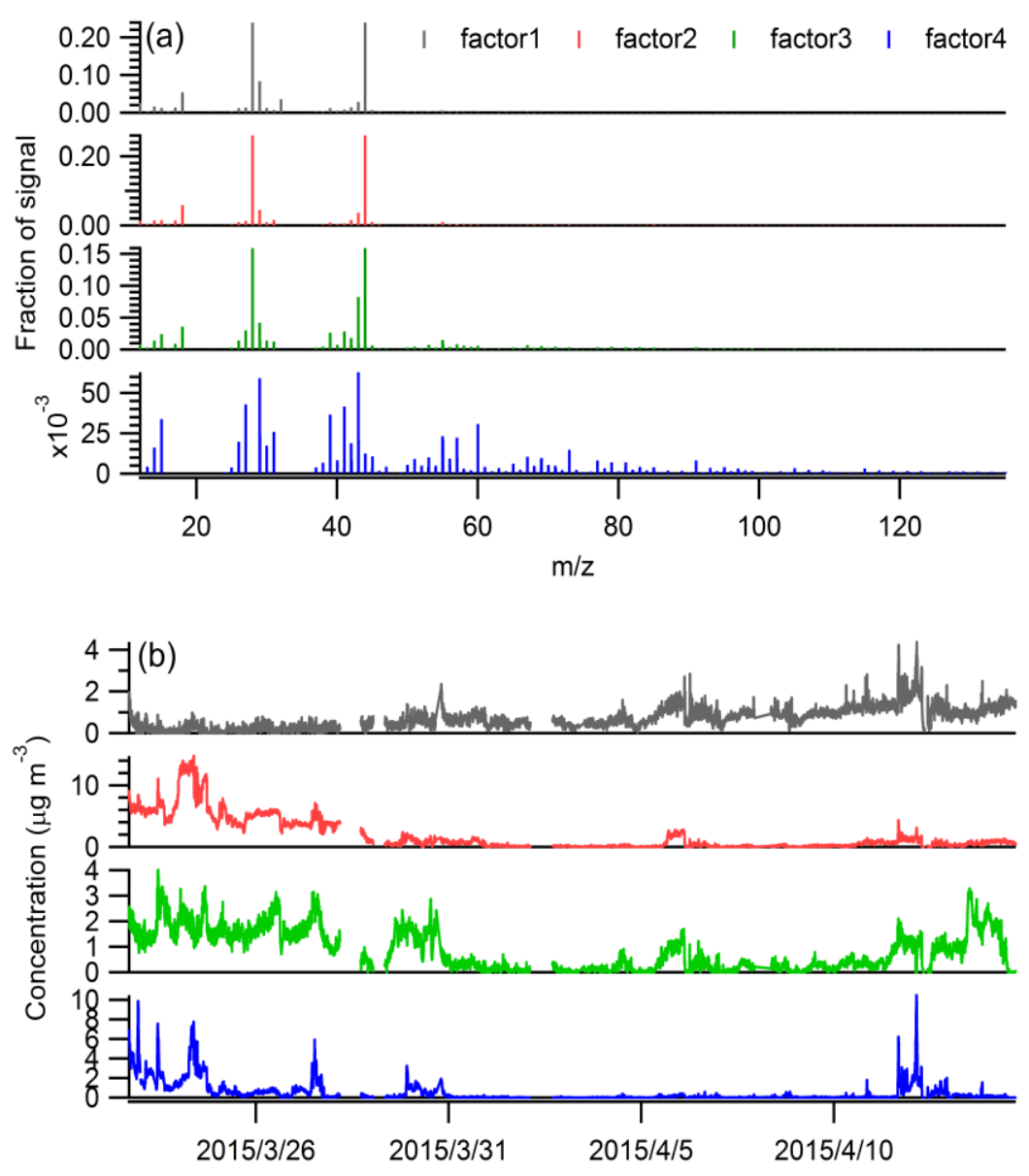

Figure S3. (a) mass spectra and (b) time series of the 4-factor solution. 


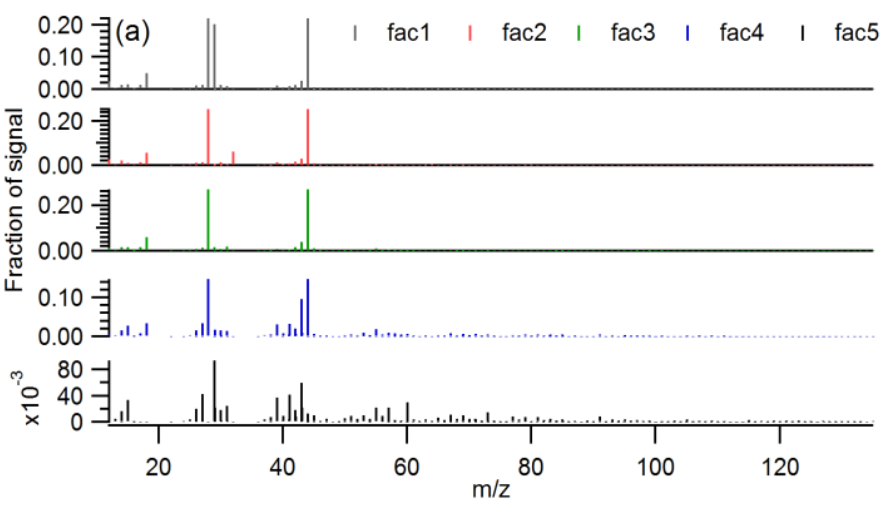

(b)
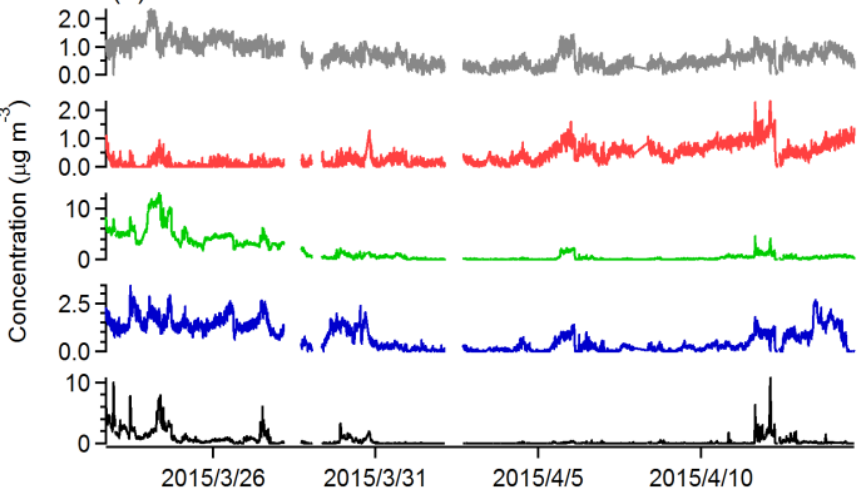

41

Figure S4. (a) mass spectra and (b) time series of the 5-factor solution. 

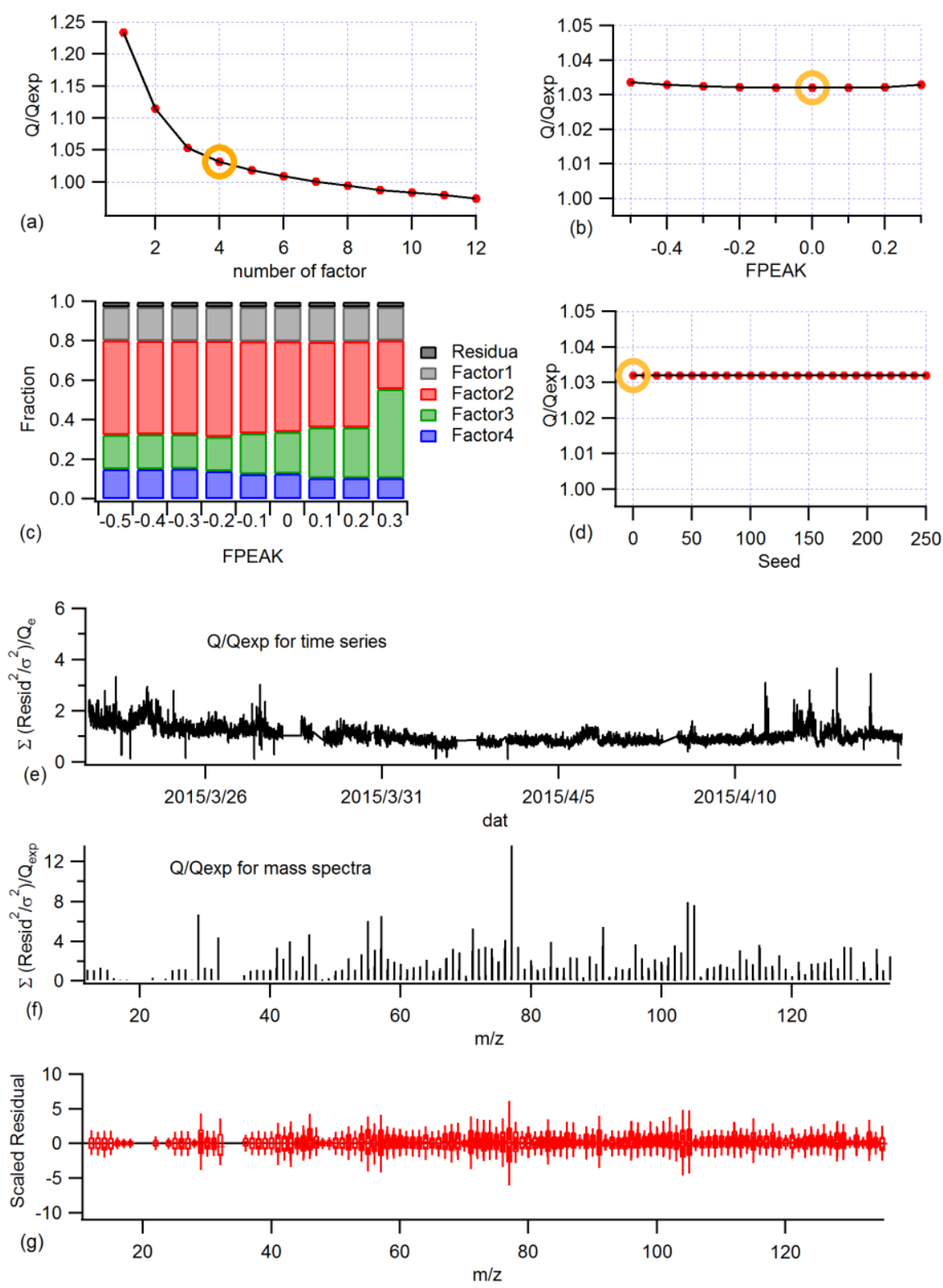

Figure S5. Diagnostic plot of PMS solution. Panel (a) the Q/Qexp values as a function of factor number; (b) the Q/Qexp 46 values as a function of FPEAK values of 4 factor solution; (c) relative contribution of four OA factors of different FPEAK

47 values; (d) the Q/Qexp values as a function of seed values of 4 factor solution; (e) time series of the Q/Qexp values; (f) the $\mathrm{Q} / \mathrm{Q} \exp$ values of different $\mathrm{m} / \mathrm{z}$; $(\mathrm{g})$ the box-whisker plot for the scaled residual for the mass spectra. 


\section{Reference}

51 Gysel, M., Crosier, J., Topping, D. O., Whitehead, J. D., Bower, K. N., Cubison, M. J., I.Williams, P., Flynn, M. J., McFiggans,

52 G. B., and Coe, H.: Closure study between chemical composition and hygroscopic growth of aerosol particles during TORCH2, 53 ACP, 7, 6131-6144, 10.5194/acp-7-6131-2007, 2007.

54 Hu, W. W., Hu, M., Yuan, B., Jimenez, J. L., Tang, Q., Peng, J. F., Hu, W., Shao, M., Wang, M., Zeng, L. M., Wu, Y. S., Gong, 55 Z. H., Huang, X. F., and He, L. Y.: Insights on organic aerosol aging and the influence of coal combustion at a regional receptor 56 site of central eastern China, Atmos. Chem. Phys., 13, 10095-10112, 10.5194/acp-13-10095-2013, 2013.

57 Middlebrook, A. M., Bahreini, R., Jimenez, J. L., and Canagaratna, M. R.: Evaluation of Composition-Dependent Collection 58 Efficiencies for the Aerodyne Aerosol Mass Spectrometer using Field Data, Aerosol Sci. Technol., 46, 258-271, $59 \quad 10.1080 / 02786826.2011 .620041,2012$.

60 Ulbrich, I. M., Canagaratna, M. R., Zhang, Q., Worsnop, D. R., and Jimenez, J. L.: Interpretation of organic components from 61 Positive Matrix Factorization of aerosol mass spectrometric data, Atmos. Chem. Phys., 9, 2891-2918, 10.5194/acp-9-2891$62 \quad 2009,2009$.

63

64

65 